\title{
UM ESTUDO ACERCA DO PERFIL DE CONSUMO CULTURAL DOS ALUNOS DA UNIVERSIDADE FEDERAL DO CEARÁ
}

\section{A RESEARCH ON THE PROFILE OF CULTURAL CONSUMPTION OF THE STUDENTS OF THE FEDERAL UNIVERSITY OF CEARÁ, BRAZIL}

\author{
Thiago Andrade Sales ${ }^{1}$ \\ Pablo Urano de Carvalho Castelar ${ }^{2}$ \\ Alesandra de Araújo Benevides ${ }^{3}$
}

\section{Resumo}

Este trabalho busca estudar o comportamento de consumo de bens culturais pelos alunos da Universidade Federal do Ceará - UFC. Utilizou-se como forma de captura e instrumentalização dos dados o uso de um questionário para que fossem observados aspectos econômicos e sociais dos agentes, assim como perguntas mais direcionadas à sua forma de consumo cultural, frequência de uso e grau de importância desses bens. A partir disso, foi elaborado um modelo probit em que se analisa o comportamento do consumo de bens culturais mediante algumas variáveis exógenas como: a utilização de bens culturais dentro da universidade; anos de estudo nos cursos de graduação na universidade; idade dos estudantes; renda e sexo. Verificou-se que a utilização de bens culturais disponibilizados pela universidade tende a aumentar o consumo de bens culturais, assim como em relação aos anos de estudo dos agentes nos cursos de graduação. No entanto, à medida que os alunos aumentam de idade, seu consumo de cultura tende a diminuir, e parece haver um desconexo entre disponibilidade de equipamentos culturais e percepção dos discentes a respeito desta oferta.

Palavras-chave: Consumo cultural; Universidade Federal do Ceará; Modelo Probit.

\begin{abstract}
This work seeks to analyze the behavior of the consumption of cultural goods by the students of the Federal University of Ceará - UFC. A questionnaire was used as a way of capturing and manipulating the data so that economic and social aspects of the agents could be observed, as well as more questions related to their cultural consumption, frequency of use and degree of importance. From this, a probit model was elaborated in which the behavior of the consumption of cultural goods is analyzed through some exogenous variables such as: the use of cultural goods within the university; Years of study in undergraduate courses at the university; Age of students; Income and sex. It was verified that the use of cultural goods made available by the university tends to increase the consumption of cultural goods in general, as well as in relation to the years of study of the students in undergraduate courses. However, cultural consumption seems to decrease as age increases, and there seems to be a disconnect between the availability of cultural goods and the perception of the students about the supply of such goods.
\end{abstract}

\footnotetext{
${ }^{1}$ Formado em Finanças - Universidade Federal do Ceará. .E-mail : thandrsales@gmail.com

2 Curso de Finanças/Universidade Federal do Ceará. E-mail : pcastelar@ufc.br

${ }^{3}$ Cursos de Finanças e Ciências Econômicas/Universidade Federal do Ceará -Campus Sobral. Email : alesandra@ufc.br
} 
Keywords: Cultural Consumption; Federal University of Ceará; Probit Model.

JEL: Z10, Z18, Z11

\section{INTRODUÇÃO}

Observando-se a própria estrutura cultural presente no Brasil, percebe-se a grande variedade cultural elencada nos grupos e comunidades que constituem o país. A necessidade de que se entenda suas significações subjetivas e materiais, assim como seus simbolismos na formação da identidade cultural destes sujeitos, se mostra bastante importante na compreensão do impacto dos bens ditos culturais e artísticos dentro das relações sociais e econômicas estabelecidas por esses agentes.

O universo do ensino público universitário é um ambiente propício para análise, devido à heterogeneidade de seu público, em termos de classe social, raça, gênero, mas certa padronização no nível educacional, de um público jovem que, a priori, anseia por cultura e novos descobrimentos, em instituições que instigam e fornecessem aparato cultural para consumo.

Este trabalho busca analisar a cesta de bens culturais e artísticos dos alunos da Universidade Federal do Ceará. Foi aplicado um questionário socioeconômico a fim de capturar as características e argumentos necessários para a análise do consumo cultural e artístico desses agentes econômicos, bem como suas preferências de consumo, frequência e distribuição.

Segundo Geertz (1989), o conceito que abarca cultura se performa através de teias de significados construídas pelo homem; significações que refletem as ações dos sujeitos e a eles próprios em suas individualidades, assim como suas relações econômicas, pertencentes às suas ações humanas. A cultura possuiria, então, uma estrutura semântica e deveria ser analisada como uma escritura construída pelos homens a partir de seus processos de simbolismos e subjetivações dos seus materialismos social e cultural.

Mais importante do que apenas identificar essas dinâmicas e relações culturais na estrutura simbólica das ações dos indivíduos em seus grupos, é preciso sabê-las interpretar de forma densa para que se compreenda as relações construídas por eles, presentes nas interações entre os agentes de uma economia (GEERTZ, 1989).

Mais especificamente dentro da perspectiva econômica, os bens culturais são produtos obtidos a partir do processo produtivo da cultura, do artesanato ou da indústria, os quais propiciam aos agentes econômicos o acesso ao conhecimento e aprendizagem, na construção de sua própria identidade, e na percepção coletiva em que está inserido; conceito que vem adquirindo bastante visibilidade nas formulações de políticas públicas culturais que influem nas questões de cidadania, direitos de acesso à cultura e identidade cultural.

$\mathrm{Na}$ busca de se diferenciar, bens culturais de produtos culturais, Coelho Netto (1997) nos traz a discussão acerca dos bens culturais possuírem valor subjetivo e simbólico próprios.

O valor cultural desses bens específicos também pode ser sentido em sua capacidade de trazer à memória estímulos vinculados a aspectos subjetivos dos sujeitos, fortalecendo o acesso à cultura, como também no percurso formativo de sua identidade cultural e social. Destarte, o preço cultural desses bens estaria relacionado não apenas à disposição dos agentes econômicos em dispender renda para que possam ter acesso a esses produtos. 
Nos últimos anos, tem-se dado uma maior visibilidade aos setores da economia relacionados à cultura e à arte, principalmente em ações e atividades do Estado em se tratando de diretrizes atreladas às políticas públicas, como pode ser mencionado o fortalecimento da Lei Rouanet, em 1991, e a Lei do Audiovisual, em 1993, garantindo o aparelhamento legal de apoio ao fomento de dispositivos e circuitos artísticoculturais, como também em termos de ampliação de sua oferta.

Essas ações políticas, por meio da elaboração e execução de leis de apoio à cultura e arte propiciam, dessa maneira, a maior participação dos mercados culturais na economia nacional, mostrando a importância da indústria cultural em termos de benefícios auferidos, aumentando o número de projetos assistidos por editais públicos de financiamento e incrementando, nos setores da economia, valores bastante significativos, além do incentivo ao consumo cultural decorrente.

A questão de pesquisa apresentada justifica-se, principalmente, pela falta de estudos com esse escopo, pela necessidade de compreensão dos mercados de bens culturais, dado seu crescimento e importância nas práticas de consumo, pela oportunidade de se proporcionar aumento da base de literatura acerca da temática e pela possibilidade de que ela sirva como instrumento de análise para organizações públicas e privadas as quais possuam interesse sobre o comportamento de consumo de bens culturais do público especificado.

Com isso, o intento deste trabalho é averiguar a questão do consumo cultural no ambiente específico de uma universidade pública brasileira, para intuir sobre políticas culturais que abrangem essa amostra da sociedade. De forma específica, o objetivo do trabalho é descrever as características do consumo de bens culturais e artísticos dos alunos da Universidade Federal do Ceará, permitindo conjecturar sobre o interesse e o consumo da população de bens de tal categoria.

Além desta introdução, este artigo está traz uma revisão bibliográfica, uma seção sobre a metodologia empregada no tratamento dos dados obtidos por meio do questionário elaborado para aplicação e construção do modelo probit; a análise dos dados e resultados obtidos e, por fim, a conclusão com possíveis sugestões e encaminhamentos sobre o tema.

\section{CULTURA E DESENVOLVIMENTO}

É importante observar que a definição do que é desenvolvimento vem sendo modificada ao longo dos tempos com a inclusão de fatores mais amplos, como a participação dos dispositivos culturais e seus impactos nos indicadores de desenvolvimento. Entender que cultura e desenvolvimento estão fortemente correlacionados, mas que, per si, são processos sociais independentes, também se faz necessário, no sentido de que o contexto cultural condiciona o desenvolvimento de um dado sistema, mas não é causa (SILVA E ARAÚJO, 2010).

A Constituição Federal de 1988 traz em seu texto os direitos culturais como um dos alicerces das bases para a execução e implementação de um desenvolvimento ótimo, respeitando as matrizes culturais diversas existentes no processo de formação da sociedade, buscando reconhecer suas pluralidades constituintes e seus aspectos culturais similares. A União, os estados e municípios possuem a competência de propiciar realidades de incentivo e fomento de ações que visem à produção de cultura. "O mercado interno integra o patrimônio nacional e será incentivado, de modo, a 
viabilizar o desenvolvimento cultural e socioeconômico do país, o bem-estar da população e autonomia tecnológica do país" (BRASIL, 1988).

A cultura influi no processo dinâmico da formação das identidades dos agentes, tendo em vista que desenvolvimento implica melhorias nas condições de vida e de existência, assim como as possibilidades de suas potencialidades nas expressões de seus modos simbólicos de ser. As ações de políticas culturais passam a ser transversais quando tangenciam as instituições que são responsáveis pela formação básica desses agentes, na observância de suas diversidades e de garantias de acesso aos direitos culturais.

A bandeira desenvolvimentista ${ }^{4}$ traz consigo os emblemas dos direitos fundamentais, nos quais é possível encontrar os direitos relacionados à democracia cultural, sendo esta, um processo integrado. Há que se levar em consideração a magnitude e dimensão territorial do país, a movimentação dos fluxos de intercâmbio e as vias de fortalecimento regional das culturas, deixando as políticas culturais mais complexas e de efeitos mais ampliados (SILVA E ARAÚJO, 2010).

A relação entre individualidade/personalidade e construção cultural social é percebida pela observação da distribuição e performance de consumo cultural, ambientadas no contexto de influência midiática e de consumo. Também levanta a questão do uso dos bens culturais como forma de diferenciação e participam da formação da nossa singularidade enquanto indivíduos, revelando que a forma de como esses itens são conceituados e utilizados são fatores mais pertinentes do que apenas seu consumo per si (FREIRE FILHO, 2003)

A valorização das matrizes constituintes da diversidade cultural, no que se refere à valorização e promoção das diferenças sem acarretar sua homogeneização pelas trocas, gera certos fins de garantias de construção de uma cultura comum onde caibam os processos de fortalecimento da identificação com os bens e serviços oferecidos pelas manifestações culturais (SILVA E ARAÚJO, 2010).

Dentro desse escopo de crescimento das demandas culturais na economia em geral, é pertinente citar o IDECULT, que consiste no Indicador de Desenvolvimento da Economia da Cultura, o qual mensura o processo de desenvolvimento da cultura a partir da leitura analítica e estatística de informações como o nível de consumo cultural das famílias, as disponibilidades de equipamentos culturais e o mercado de bens e serviços culturais no âmbito municipal do país, assim como também permite avaliar a distribuição dos agentes utilizadores desses tipos de bens e serviços (SILVA $E$ ARAÚJO, 2010).

O IDECULT apresenta certos percalços em sua natureza como a limitação em não conseguir captar processos que não sejam quantificáveis, processos em seu estado latente que não apresentem formas viáveis de observação e captação por meio de variáveis instrumentais observáveis, ações relativas ao patrimônio imaterial, como também a dificuldade na observação de percursos formativos de atividades culturais amadoras e que não sejam monetizadas (SILVA E ARAÚJO, 2010).

Essa forma de estruturação na elaboração do IDECULT permite que seja utilizado no que se refere às elaborações de políticas públicas e ações privadas de cultura, na decisão de investimentos, subsídios, incentivos, distribuição de

4 O termo desenvolvimentista utilizado por Silva e Araújo (2010) refere-se aqui à terminologia presente na Constituição Brasileira de 1988 que denota qualquer tipo de política voltada para o desenvolvimento econômico, e não a política econômica do chamado nacional-desenvolvimentismo, adotado na América Latina a partir de 1930. 
equipamentos, análise de custos e avaliação das efetividades desses processos culturais de trocas entre os agentes receptores e organizadores.

A análise capturada a partir desse indicador de desenvolvimento da cultura leva em consideração os equipamentos culturais como objetos relativos ao consumo e utilização dos bens pelos agentes assim como sua distribuição entre os municípios. Os equipamentos culturais são dispositivos que englobam e se relacionam com as práticas culturais dos agentes que usufruem de bens e serviços culturais (SILVA E ARAÚJO 2010).

Percebe-se que a distribuição e oferta desses dispositivos culturais estão correlacionadas com o nível de desenvolvimento regional em que se situam, mostrando-se assim que ainda se faz necessário o melhor entendimento de suas disponibilidades no fortalecimento das garantias para os agentes.

Dessa maneira, analisar o desenvolvimento da economia da cultura, no seu percurso, tangencia de forma direta as vias de consumo dos produtos culturais que circulam pelos mercados de trocas simbólicas com esferas econômicas, revelando as dinâmicas culturais das práticas e expressões simbólicas dos agentes da cultura.

\section{REVISÃO DE LITERATURA}

A economia da cultura é uma área de pesquisa vasta e que tem crescido a cada ano desde a publicação do trabalho seminal de Baumol e Bowen, em 1966, chamado Performing Arts: The Economic Dilemma. É evidente que, ainda no século XVIII, estudiosos como Mandeville e Hume já discutiam a demanda de mercado das artes e as externalidades positivas por elas provocadas (GOODWIN, 2006). Entretanto, a partir da obtenção de dados e com o desenvolvimento da teoria econômica, aspectos ligados à demanda por arte e bens culturais (BRITO; BARROS, 2005; CHUNG; SONG, 2008; DINIZ; MACHADO, 2011; CASTIGLIONE; INFANTE, 2016), ao comportamento do consumidor (FAVARO; FRATESCHI, 2007; MASON, 1992), à produção de bens artísticos (BRYANT; THROSBY, 2006; THROSBY, 1999; CHENG, 2006), ao mercado de trabalho (MENGER, 2006; WASSALL; ALPER, 1992), às políticas públicas voltadas para o mercado cultural (ROBBINS, 1963; PIETRORODRIGUEZ et al., 2005; GALLOWAY; DUNLOP, 2007; HESMONDHALGH, 2005), entre outros levaram a discussão sobre economia da cultura a um outro patamar.

Como o campo é extenso devido à diversidade de abordagens, o foco maior desta revisão da literatura será sobre os aspectos da demanda por arte e bens culturais, bem como o comportamento do consumidor diante destes bens e serviços e o financiamento pelo setor público. A modelagem de adicção ou hábito tem sido utilizada por pesquisadores. Entre eles, Brito e Barros (2005) investigaram o comportamento das preferências do consumidor, elaborando dois modelos teóricos de equilíbrio agregado para explicar este comportamento. Observou-se que, no curto prazo, o consumidor vai aprender a consumir (hábito) à medida em que consome. Este comportamento é caracterizado pela complementariedade entre o estoque de cultura e a riqueza financeira dos indivíduos. $O$ ajuste da demanda por bens culturais (ou dos preços relativos) terá alguma inércia. Além disso, um aumento na renda real levará a um melhoramento no estoque de cultura, aumentando a demanda por bens culturais, se os preços forem fixos. Caso sejam flexíveis, esta elevação na renda levará a um aumento nos preços (BRITO; BARROS, 2005) 
Em uma aplicação empírica do modelo de adicção racional ${ }^{5}$, Castiglione e Infante (2016) testaram a hipótese de formação de hábito para os espectadores de teatro italianos. Foram analisados dados de frequência anual de teatros regionais em painel para 34 anos. Os autores verificaram que os preços passados e futuros influenciam somente de maneira indireta a frequência atual dos teatros. Embora o consumo de teatro seja adictivo, uma vez que o consumo passado e os preços aumentam a utilidade marginal atual do consumo do indivíduo, o espectador não é míope em relação ao consumo. Ou seja, o hábito não se insere de maneira prejudicial na vida destes consumidores (CASTIGLIONE; INFANTE, 2016).

$\mathrm{Na}$ Coreia do Sul, observou-se que a probabilidade de assistir a um filme estrangeiro aumenta $75,9 \%$ se os elementos culturais deste filme fossem trocados por elementos culturais coreanos (CHUNG; SONG, 2008). Utilizando dados de quantidade de espectadores para 764 filmes apresentadores entre 2002 e 2004, os autores estimaram a função de utilidade indireta e computaram a semi-elasticidade da demanda dos coreanos. A disposição a pagar mais por elementos culturais nacionais comparativamente a elementos estrangeiros nos diversos filmes foi significante.

Ainda no que concerne à demanda por bens culturais, observa-se que o consumo de gêneros musicais na Itália está correlacionado a características dos indivíduos como sexo, idade, nível educacional, entre outras (FAVARO; FRATESCHI, 2007). Os autores fizeram uma análise empírica e estimaram um modelo logit multinomial para verificar se o gosto musical dos italianos é diversificado. Com dados da pesquisa "Cidadãos e Lazer", realizada pelo Instituto Nacional de Estatística da Itália em 2000, Favaro e Frateschi (2007) concluíram que estar entre 34 e 60 anos, ser do sexo feminino e ter um nível educacional elevado (ensino médio ou mais) contribui para uma trajetória de comportamento esnobe e/ou diversificada no tocante a gosto musical.

A demanda por bens culturais é influenciada fortemente pelo comportamento de um patrocinador importante: o Estado. Há argumentações favoráveis e contrárias ao incentivo fiscal, mas é incontestável que o governo joga um papel importante no setor (ROBBINS, 1963). Para o autor, o fato de o Estado ser provedor e dar suporte às artes não contradiz os princípios de uma sociedade livre, desde que não haja monopólio do Estado como um ditador artístico.

A situação dos artistas ao redor do mundo apresenta muitas semelhanças, com empregos vulneráveis e esporádicos e nível de renda com alto grau de risco e incerteza (FREUDENBERG, 2011). Tudo isto leva a argumentos favoráveis que justificam a intervenção fiscal estatal. Entretanto, Freudenberg (2011) aplicou uma pesquisa com 236 indivíduos do meio artístico da Austrália no intuito de captar o entendimento do setor sobre a forma como acessam informações fiscais e qual seria o nível de competência destas pessoas para lidar com obrigações fiscais. Não raro, os respondentes colocam seus agentes como fonte de informações fiscais. Além disso, o autor questiona a capacidade de os artistas lidarem com obrigações tributárias.

Prieto-Rodriguez et al. (2005) realizaram microssimulações de reformas fiscais sobre bens culturais para observar a progressividade ou não do setor na Espanha. Utilizando um modelo AIDS 6 para estimar as elasticidades da demanda por 19 tipos de bens - entre eles, três tipos de bens culturais, as três microssimulações de reforma

${ }^{5} \mathrm{O}$ modelo avalia o impacto de preços futuros sobre a formação de hábito.

${ }^{6}$ Almost Ideal Demand System

90 Economia \& Região, Londrina (Pr), v.7, n.1, p.85-106, jan./jun. 2019 
fiscal propostas revelaram uma tendência ao aumento da desigualdade na distribuição de gastos e reduziram também a progressividade do imposto indireto (sobre valor adicionado). Portanto, se a política pública for meramente fiscal, haverá ganhos de bem-estar que serão mais apropriados pelos indivíduos com melhor situação econômica (PRIETO-RODRÍGUEZ; ROMERO-JÓRDAN; SANZ-SANZ, 2005).

Esta discussão mostra que não é pacífica a ideia de subsidiar e dar suporte ao setor cultural-artístico por parte do governo. Será preciso considerar a distribuição do benefício fiscal e não somente levar em conta que há externalidades positivas e bens públicos imbricados na partilha.

Considerando abordagens da cultura e seu consumo no Brasil, em seu artigo, Forjaz (1988) analisa as práticas e representatividades das atividades de lazer e o consumo de bens culturais na área metropolitana da cidade de São Paulo. $O$ levantamento de dados se deu apenas com a classe empresarial, impossibilitando assim, uma comparação entre as classes econômicas. Sendo assim, o estudo teve como escopo o núcleo familiar de empresários da cidade de São Paulo. A metodologia abordada se deu por meio de entrevistas direcionadas aos filhos, esposas e aos empresários, os quais deveriam ter renda superior a 60 salários mínimos para participação da amostragem.

Os bens mais consumidos por esse setor social são aqueles oriundos da indústria cultural, vinculados à "cultura erudita": revistas, livros, cinema, rádio, televisão dentre outros, muitas vezes em espaço doméstico e familiar. A autora constata que não há, para essa amostra, uma separação nítida entre trabalho e lazer, sendo, inclusive, duas atividades atreladas para os agentes, os quais consomem principalmente artigos advindos da indústria cultural, de forma não-individualizada, em âmbito domiciliar e geralmente investem, também, em formas de lazer associada a esportes e bem-estar.

Goldenstein (1991) trata de como são distribuídas as práticas de lazer e a forma de como essas práticas são incorporadas pelos operários, usando como amostra 60 operários, que foram escolhidos para análise de variáveis referentes a idade e sexo, na região metropolitana de São Paulo nos anos 1980, usando como grupo comparativo, amostras com mesma dimensão composta por sujeitos da classe média e alta.

Faz-se, então, uma análise detalhada do consumo cultural desses operários. Os agentes são parcialmente excluídos de muitos equipamentos culturais existentes e não possuem nível significativo de consumo cultural. As práticas culturais, quando realizadas, são mais frequentemente executadas em ambientes domiciliares.

Rondelli (1998) traz a análise das novas definições de consumo geradas pelo aumento da participação de segmentos sociais populares no consumo de bens culturais, levando em consideração seu aumento de poder de compra, principalmente de aparelhos televisores, atrelado a sua maior inserção no mercado de TV por assinatura.

Discute-se o tema "Consumo e subjetividade" também dentro da perspectiva de globalização, atentando para que se continue o estudo sobre a temática pela importância a que está relacionada nos processos determinadores das performances sociais e culturais dos agentes. Realiza-se um levantamento histórico sobre as principais teorias que tratam do consumo como um processo de características sociais e culturais na aquisição de bens e serviços, considerando as consequências do consumo em termos de subjetividade (MANCEBO et. al., 2002). 
Felix (2003) traz em, "Juventude e estilo de vida: cultura de consumo, lazer e mídia", um esboço sobre a relação entre os estilos de vida, tipos de lazer e consumo pelos agentes mais jovens e como estes agentes percebem o meio em que estão inseridos, como o incorporam nessas esferas e como esse processo influencia a elaboração dos seus processos identitários em contato com símbolos culturais sem fronteiras, espaços virtuais de comunicação e sociabilidade.

Freire Filho (2003) trata da relação de individualidade, personalidade e construção cultural social a partir da distribuição de consumo cultural, ambientando essa relação no contexto da influência midiática e do consumo; trazendo também a questão do uso dos bens culturais como forma de distinção social, revelando que a forma como esses itens são conceituados e utilizados são fatores mais pertinentes do que apenas seu consumo.

Ferreira (2003) aborda a forma de como os vestibulandos de quatro universidades públicas da cidade do Rio de Janeiro em 1990 perfazem seu estilo de vida e o capital cultural. Foram levantados os ambientes sociais, as ações culturais e práticas de lazer que o grupo-sujeito escolhe em termos de consumo cultural.

O autor elaborou um questionário para levantamento das características socioculturais dos agentes, sendo possível estabelecer correspondência entre elas e suas demandas por consumo cultural. Conclui-se que, dentro das alternativas disponibilizadas aos agentes, ainda persistem consideráveis disparidades na acessibilidade dos bens culturais por parte desses sujeitos e que, no Brasil, diferentemente do que ocorreu na França, onde Bourdieu (1996) apud Ferreira (2003) fez associação entre recursos financeiros e capital cultural, não apresentando a mesma natureza quanto à relação positiva entre esses dois fatores.

Nunes (2007) analisa a relação entre o espaço urbano e os agentes mais jovens dentro das suas relações de consumo como instrumento performativo de seus processos de construção de identidade, detectando que o estado social menos abastado torna os agentes mais frágeis socialmente, modificando o seu modo de consumir, além de criar certas resistências de consumo.

Da Silva, Araújo e Souza (2007) utilizam dados da POF de 2002-2003 para analisar o consumo cultural no Brasil. A maneira como os agentes utilizam seu tempo livre e a forma de que investem no consumo de dispositivos culturais são apresentadas pela POF. Os autores demonstram a presença de enorme heterogeneidade relativa ao comportamento de consumo cultural no país, a qual deve ser considerada na construção de políticas públicas que tratem dos argumentos culturais. As relações culturais advindas dos sistemas culturais são bastante valorizadas pelos agentes usufruidores desses dispositivos culturais. $O$ incentivo público percebido às atividades culturais relativas a espetáculos e cinemas não acompanha o consumo desses bens e serviços culturais pelos agentes. Observa-se também a televisão é a mais recorrida quando tratamos de consumos de lazer, estando presente em quase todos os domicílios. Entretanto o consumo pelos agentes referentes a jornais, por exemplo, é elevado, embora não seja distribuído amplamente como o caso dos televisores (DA SILVA, ARAÚJO E SOUZA, 2007).

Diniz e Machado (2009) analisa o consumo de bens e serviços de natureza artística e cultural nas metrópoles brasileiras. São examinados os fatores que influenciam e determinam o consumo de bens e serviços de arte e cultura no país, levando em conta que o consumo cultural e artístico acarreta bons resultados para quem o consume e para a sociedade per si. O consumo, hoje, desses bens específicos, assim como os serviços de mesmo escopo simbólico, é principalmente determinado pelo grau de contato prévio a esses tipos de bens e serviços. 
A renda e a educação do consumidor desses tipos de bens, segundo os resultados obtidos pelo modelo utilizado, são os fatores que mais influem e determinam o dispêndio em arte e cultura nas metrópoles brasileiras. As disparidades regionais acerca das diferenças históricas e culturais entre as regiões analisadas e a oscilação de oferta ocasionam uma mudança significativa do grau de dispêndio nessas regiões, correlacionando-se com as disparidades de estrutura social e cultural brasileira, trazendo o questionamento de que a elaboração das políticas públicas culturais devem levar em consideração, não apenas o incremento da oferta desses bens, mas estimular o consumo por meio da garantia da acessibilidade dos agentes a esses territórios culturais e artísticos.

Bermúdez (2010) trata sobre a reflexão teórica presente na relação entre consumo cultural e construção das representatividades de identidades cultural dos jovens de Maracaibo, na Venezuela, na perspectiva de globalização. Assim como as transformações que essa construção de representação simbólica de suas identidades tem sofrido.

Paglioto e Machado (2012) estudam o perfil dos frequentadores de atividades culturais nas metrópoles do país. Analisam as características relacionadas à frequência dos sujeitos em eventos de cultura, onde existe desembolso financeiro como pagamentos para aquisição de ingressos. Utiliza-se neste trabalho um modelo probit, para que seja estimada a probabilidade de que esse desembolso ocorra, considerando os anos de 2002-2003 e 2008-2009, assim como os aspectos que constroem o perfil desse consumidor médio potencial em mercados culturais, assim como fatores que influenciam no uso desses ambientes como tempo livre, efeito de "vício positivo" como trazido por Stigler e Becker (1977). Em termos de consumo fora da residência, os fatores que mais influenciam esses sujeitos são a renda e a escolaridade.

Castelar, Castelar e Benevides (2012) têm como objetivo de análise a determinação das variáveis reais que influem para o dispêndio cultural dos agentes que se alocam sob a linha de pobreza de consumo cultural, realizando comparações com outros setores sociais mais abastados.

A elaboração de um índice individual de consumo cultural se deu como dispositivo de análise na compreensão desses gastos em 21 bens e serviços de cultura, assim como variáveis sociais, econômicas e demográficas desses agentes em relação ao índice construído. Como metodologia, estima-se um modelo por regressão quantílica, obtendo-se respostas as quais convergem para o fato de que os agentes que se encontram abaixo da linha de pobreza de consumo em cultura possuem uma sensibilidade menor aos argumentos que determinam o índice de consumo em cultura estabelecido, sendo este índice reduzido consideravelmente quando se tem agentes com variáveis correspondentes do sexo masculino.

Earp e Paulani (2014) analisam as mudanças no consumo de bens culturais no Brasil logo após a estabilização da moeda. Os autores possuem como objetivo específico a explanação clara acerca das disparidades entre o incremento geral do consumo dos domicílios do Brasil depois da implantação do real e a performance dos bens culturais, mostrando a priori uma correlação ascendente entre estabilização da moeda e consumo cultural.

Bem, Waismann e Finnatto (2014) analisam a transfrormação do consumo de bens culturais nos domicílios particulares ao longo do tempo, focando no município gaúcho de Canoas, no período entre 2000 e 2010 . A argumentação dos autores é de que as pessoas, com o passar do tempo, mudam seus hábitos de consumo e as 
preferências também se alteram no que concerne aos bens culturais. Dentre os motivos desta alteração estão aspectos como os preços dos produtos, a idade do consumidor, sua renda, sua educação. O município de Canoas é o segundo maior do estado em termos de PIB per capita, mas no que diz respeito ao consumo de bens culturais, os autores concluem que nos domicílios da localidade, embora acompanhem os movimentos do Rio Grande do Sul, têm uma composição superior em produtos com maior grau tecnológico, desde o ano de 2000.

O intuito dessa breve revisão, assim, não é de exaurir o assunto, mas demonstrar como há uma pletora de abordagens e perspectivas a respeito discussão da cultura e seu consumo. Para o presente trabalho, o foco será analisar um microcosmo consumidor de cultura, e associar as escolhas e interesses dos alunos universitários da Universidade Federal do Ceará, nos seus mais diversos cursos, com as intuições colhidas na literatura apresentada acima. Principalmente, os trabalhos mais recentes, como Silva, Araújo e Souza (2007) e Castelar, Castelar e Benevides (2012), são utilizados como referêcia a respeito da intuição por trás do consumo aparente da amostra.

\section{ASPECTOS METODOLÓGICOS}

\section{Base de Dados}

Na busca pela compreensão da complexidade dos fenômenos, podemos utilizar instrumentos específicos para essa análise, como a observação da realidade, a utilização de questionários para captura das informações ou a elaboração de modelos que visem a explicar a realidade em análise (KISH, 1987).

Nesse trabalho, foi utilizado um questionário para levantar os dados e informações necessárias para a análise e discussão dos objetivos estabelecidos, assegurando a melhor representatividade e generalização para a população da amostra.

A partir dos objetivos gerais e específicos de pesquisa e do público-alvo, formulase as perguntas devem estar intimamente ligadas a temática da pesquisa, aumentando o grau de coerência entre elas e o tema da análise, visando à captação das informações. A amostra, da mesma forma, deve seguir de acordo com os objetivos específicos da pesquisa, sendo ela composta por sujeitos que representem fielmente a população em análise.

Dessa maneira, há uma relação forte entre a aplicação do questionário e a estruturação em que foi construído, considerando que o nível de complexidade dos conceitos influencia na quantidade de perguntas e como elas devem ser apresentadas aos sujeitos da pesquisa. As características da amostra determinam como será elaborado o questionário, conferindo-Ihe orientações e ajustamentos necessários quanto à forma, tamanho e estrutura, assim como a maneira em que será administrado (GÜNTHER, 2003).

Em se tratando da mensuração das variáveis usadas na elaboração dos instrumentos de captura de dados e informações, como os questionários, precisa ser fortalecida a correspondência entre os fenômenos estudados e os argumentos que constroem o questionário para que possam ser sensíveis a variações nos eventos em análise, abarcando-as (GÜNTHER, 2003).

Para isso, existem quatro principais escalas para mensuração, são elas: nominal, ordinal, intervalar e razão, para construção de questionários que possuam a 
capacidade de fazer correspondência entre os fenômenos estudados e os argumentos do questionário (PASQUALI, 1997; SIEGEL, 1975).

O poder das inferências e análises estatísticas está relacionado com a escolha da técnica de escala de mensuração utilizada, sendo que escalas nominais e ordinais podem ser melhores instrumentos para testes estatísticos não-paramétricos com uso de estatística descritiva. Os dados obtidos por meio de escalas intervalares ou de razão possibilitam a instrumentalização das informações com uso de estatística paramétrica com dados mais fortes em inferências e análises estatísticas (GÜNTHER, 2003).

O controle da variabilidade na transcrição das respostas e o controle da variabilidade na aplicação do questionário devem ser altos para que se evitem viés e perdas de informação e dados por meio do instrumento, sendo que, para tal, será utilizado um questionário produzido virtualmente, visando redução de custos e aumentando a potencialidade da captação de dados e informações pelos respondentes.

As informações e os dados utilizados neste trabalho, como base para análise dos resultados e conclusões, serão obtidos por meio da aplicação de um questionário com uso de escala paramétrica de mensuração, na tentativa de se capturar características sociais e econômicas dos alunos da Universidade Federal do Ceará, matriculados em cursos instalados nos campi da cidade de Fortaleza, que afetem o consumo cultural desses sujeitos, como também, informações e dados sobre seu grau de consumo, sua distribuição e frequência acerca de bens de produtos culturais e artísticos consumidos por eles.

Foram analisados, sob hipótese de aleatoriedade na seleção, alunos matriculados nos seguintes cursos sediados nos Campi de Fortaleza: Finanças, Jornalismo, Geografia, Engenharia Metalúrgica, Engenharia Elétrica, Engenharia Produção, Engenharia Metalúrgica, Engenharia de Pesca, Engenharia Mecânica Teatro, Publicidade, Ciências Econômicas, Ciências Contábeis, Psicologia, Enfermagem, Direito, Administração, Gestão de Políticas Públicas, Medicina, Arquitetura e Urbanismo, Economia Ecológica, Fisioterapia, Música e Ciências Biológicas.

A Universidade Federal do Ceará se constitui como uma autarquia relacionada ao Ministério da Educação, foi criada em 16 de dezembro de 1954 e instalada em 25 de junho de 1955 com sede na cidade de Fortaleza - Ceará. Hoje, comporta sete campi, sendo eles: Benfica, Pici, Porangabuçu em Fortaleza, havendo campi também em Sobral, Crateús, Russas e Quixadá. ${ }^{7}$

Dessa maneira, serão analisados 107 questionários, que foram disponibilizados e coletados ao longo de 2016, eletronicamente, e cada questionário é composto por 57 perguntas que podem ser objetivas, de múltipla escolha ou mesmo subjetivas.

\section{Modelo Probit}

Para elaboração da análise do comportamento dos agentes em relação ao seu nível de consumo em bens de cultura, utilizou-se como instrumentalização

\footnotetext{
7 Mais informações podem ser acessadas no sítio virtual: http://www.ufc.br/auniversidade/ufc-em-numeros/5891-analise-da-serie-historica-de-dados-basicos-da-ufc.
}

Acessado em 17/08/2017. 
econométrica um modelo probit com as seguintes variáveis: bcultuni, representando a utilização de bens culturais dentro da universidade; escol, referindo-se aos anos de estudo nos cursos de graduação disponibilizados pela universidade; idade2, relacionando-se com a idade dos estudantes; rendap, variável que expressa se os agentes possuíam ou não renda própria e a variável sexo.

O modelo probit surge da utilização da Função de Distribuição Acumulada (FDA) normal, que se relaciona à análise de comportamento de variáveis dependentes dicotômicas. Dessa maneira, no caso em que uma variável $X$ seguir uma distribuição normal com média $\mu$ e variância $\sigma^{2}$, sua distribuição de probabilidade acumulada será, conforme exposto em Gujarati (2006):

$$
f(x)=\frac{1}{\sqrt{2 \sigma^{2} \pi}} e^{-(X-\mu)^{2} / 2 \sigma^{2}}
$$

E sua FDA normal será da seguinte maneira:

$$
\mathrm{F}(\mathrm{X})=\int_{-\infty}^{X_{0}}\left(\frac{1}{\sqrt{2 \sigma^{2} \pi}}\right) e^{-(X-\mu)^{2} / 2 \sigma^{2}}
$$

Em que $X_{0}$ é algum valor especificado da variável $X$.

Destarte, com base na teoria da utilidade, é necessário que se elabore um índice de utilidade que seja observável (variável latente), o qual se relaciona com a escolha do agente, que é definido como função de uma ou mais variáveis explicativas do modelo, podendo ser representado da seguinte maneira, onde $X_{i}$ é uma variável característica da amostra em análise:

$$
I_{i}=\beta_{1}+\beta_{2} X_{i}
$$

Supõe-se a existência de um nível crítico do índice, conhecido como $I_{i}^{\prime}$, em que, caso o índice calculado seja maior do que o nível crítico, y $=1$ ocorre, do contrário não ocorre. O índice limiar não é observado como o índice calculado. Para ultrapassar esse percalço, diz-se que o índice de nível crítico é normalmente distribuído com mesma variância e média, facilitando assim na obtenção de informações das estimativas dos parâmetros do índice calculado, como também informações sobre o próprio índice de nível crítico não-observado.

Assegurada a proposição de que exista normalidade no modelo, podemos calcular a probabilidade de que $I_{i}^{\prime}$ seja menor que ou igual a $I_{i}$, pode ser expressa utilizando-se a FDA normal padronizada:

$$
P_{i}=P(Y=1 / X)=P\left(I_{i}^{\prime} \leq I_{i}\right)=P\left(Z_{i} \leq \beta_{1}+\beta_{2} X_{i}\right)=F\left(\beta_{1}+\beta_{2} X_{i}\right)
$$

Em que $Z_{i}$ é a variável normal padronizada. Assim, a FDA de $I_{i}$ pode ser escrita da seguinte maneira:

$$
F\left(I_{i}\right)=\frac{1}{\sqrt{2 \pi}} \int_{-\infty}^{I_{i}} e^{-z^{2} / 2} d z
$$

Substituindo $I_{i}$ pela expressão $\beta_{1}+\beta_{2} X_{i}$, temos:

$$
F\left(I_{i}\right)=\frac{1}{\sqrt{2 \pi}} \int_{-\infty}^{\beta_{1}+\beta_{2} X_{i}} e^{-z^{2} / 2} d z
$$


Assim, para que se obtenham informações sobre o índice de utilidade acerca dos seus parâmetros, toma-se o inverso da função de probabilidade $P_{i}$ :

$$
I_{i}=F^{-1}\left(I_{i}\right)=F^{-1}\left(P_{i}\right)=\beta_{1}+\beta_{2} X_{i}
$$

No modelo probit, o termo do erro não aparece em evidência como no Modelo Linear, para corrigir tal problema, pode-se utilizar o Modelo de Utilidade Aleatória, o qual permite que se observe com maior evidência o termo do erro; tendo a mesma interpretação tradicional com distribuição normal com média zero e variância $\sigma^{2}$.

O indivíduo escolhe $y=1$ caso seu nível de utilidade atrelado a essa ação de escolha exceder uma threshold, ou limite, que geralmente é dito como zero. A estimação é feita por meio do método de máxima verossimilhança baseado na distribuição de $Y$ dado que $X$ ocorra. Dessa maneira, a heteroscedasticidade em $\mathrm{V}(\mathrm{X} / \mathrm{Y})$ é considerada.

$$
L(\beta)=\pi_{y_{i}=1} F(X \beta) \underset{y_{i}=0}{\pi}(1-F(X \beta))
$$

Aplica-se log na função de verossimilhança supracitada para que se obtenham as estimativas dos $\beta$ de forma consistente, abarcados assintoticamente pela hipótese de normalidade e eficiência.

\section{DISCUSSÃO DOS RESULTADOS}

\section{Perfil da amostra}

Foram analisados 107 questionários e os resultados obtidos foram, em parte, sintetizados na tabela 1 abaixo. As variáveis observadas incluem características dos universitários, como sexo, cor/raça, características de background familiar, de renda e, obviamente, de consumo e utilização de bens e serviços culturais na cidade de Fortaleza. A Universidade Federal do Ceará tem cerca de 42 mil alunos, assim, naturalmente, a amostra dos questionários aqui analisados permite apenas uma observação local do tipo de consumo cultural dos discentes.

Conclui-se, após elencar as respostas dos questionários, que há homogeneidade da amostra nos quesitos estado civil e escolaridade (algo esperado, dado que todos são estudantes universitários), mas razoável heterogeneidade nos demais aspectos, como gênero, raça, tipo de escola estudada no ensino médio, renda familiar, escolaridade dos pais, atividade remunerada e o consumo cultural, o que permite uma análise mais segura a respeito das escolhas e acesso cultural a diferentes tipos de indivíduos, mesmo que num ambiente específico que é o da universidade pública brasilera. 
Tabela 1 - Perfil da amostra

\begin{tabular}{|c|c|c|c|c|c|}
\hline Variável & $\%$ & Variável & $\%$ & Variável & $\%$ \\
\hline sexo & & Tipo ensino médio & & Com quem reside & \\
\hline Feminino & 51,4 & Regular & 85,0 & Pais e irmãos & 46,7 \\
\hline Masculino & 48,6 & Profissionalizante & 13,1 & Pais & 21,5 \\
\hline \multirow{5}{*}{$\begin{array}{l}\text { Escolaridade } \\
\text { Superior incompleto } \\
\text { Superior completo } \\
\text { Pós-graduando } \\
\text { Pós-graduação completa }\end{array}$} & \multirow{5}{*}{$\begin{array}{c}88,8 \\
6,5 \\
3,7 \\
0,9\end{array}$} & Outros & 1,9 & Pessoa sem vínculo parental & 9,3 \\
\hline & & \multirow{6}{*}{\begin{tabular}{|l|} 
Escolaridade da mãe \\
Fundamental incompleto \\
Fundamental completo \\
Médio completo \\
Superior completo \\
Pós-graduação \\
\end{tabular}} & \multirow{6}{*}{$\begin{array}{l}12,1 \\
10,3 \\
28,0 \\
26,2 \\
15,0\end{array}$} & Outros & 14,0 \\
\hline & & & & \multicolumn{2}{|l|}{ Renda total dos pais } \\
\hline & & & & Até 1,5 salário mínimo & 15,0 \\
\hline & & & & De 1,5 a 3 salários & 22,4 \\
\hline \multirow{5}{*}{ Semestre em curso } & \multirow{5}{*}{$\begin{array}{l}22,4 \\
16,8 \\
15,0 \\
13,1\end{array}$} & & & De 3 a 4,5 salários & 17,8 \\
\hline & & & & De 4,5 a 6 salários & 13,1 \\
\hline & & Escolaridade do pai & \multirow{7}{*}{$\begin{array}{c}17,8 \\
10,3 \\
30,8 \\
18,7 \\
8,5\end{array}$} & De 6 a 10 salários & 11,2 \\
\hline & & Fundamental incompleto & & De 10 a 30 salários & 14,0 \\
\hline & & Fundamental completo & & Acesso TV por assinatura & \multirow{3}{*}{$\begin{array}{l}52,3 \\
47,7\end{array}$} \\
\hline Estado civil & \multirow{4}{*}{$\begin{array}{c}93,5 \\
5,6 \\
0,9\end{array}$} & Médio completo & & Sim & \\
\hline Solteiro & & Superior completo & & Não & \\
\hline Casado & & Pós-graduação & & \multirow{2}{*}{$\begin{array}{l}\text { Uso de equipamentos culturais } \\
\text { Nunca }\end{array}$} & \multirow{6}{*}{$\begin{array}{l}11,2 \\
46,7 \\
28,0 \\
14,0\end{array}$} \\
\hline Outros & & Atividade remunerada & & & \\
\hline Raça/Cor & \multirow{4}{*}{$\begin{array}{c}35,5 \\
55,1 \\
6,5\end{array}$} & Exerço & \multirow{4}{*}{$\begin{array}{l}46,7 \\
17,8 \\
35,5\end{array}$} & Quase nunca & \\
\hline Branco & & Nunca exerci & & Usa moderadamente & \\
\hline Pardo & & Já exerci & & Usa frequentemente & \\
\hline Negro & & Número de & & Consumo de bens culturais & \\
\hline Amarelo & 0,9 & $\mathrm{Um}$ & \multirow{5}{*}{$\begin{array}{c}43,0 \\
18,7 \\
12,1 \\
18,7 \\
7,5\end{array}$} & Baixo & 31,8 \\
\hline Indigena & 1,9 & Dois & & Moderadamente baixo & 42,1 \\
\hline Ensino médio & & & & Moderadamente alto & 21,5 \\
\hline Todo em escola privada & 60,7 & Quatro ou mais & & Alto & 4,7 \\
\hline Todo em escola pública & 34,6 & Não possui & & Perspectiva de consumo & \\
\hline Maior parte ensino privado & 2,8 & & & Aumentar consumo de bens culturais & 65,4 \\
\hline Maior parte ensino público & 0,9 & & & Manter consumo de bens culturais & 31,8 \\
\hline Parte no Brasil e parte fora & 0,9 & & & Reduzir consumo de bens culturais & 2,8 \\
\hline
\end{tabular}

Fonte: Elaborado pelos autores

A amostra é bem representada pelo sexo feminino $(51,4 \%)$ e imensa maioria formada de graduandos $(88,8 \%)$. Entre os respondentes, a maioria está no $8^{\circ}$ semestre da faculdade $(22,4 \%)$ e, portanto, finalizando o curso. Nesta amostra, os alunos da UFC são majoritariamente solteiros (93,5\%), com ensino médio feito todo em escola privada $(60,7 \%)$ e apenas $13,1 \%$ cursou um ensino profissionalizante. Chama atenção a baixa porcentagem de negros $(6,5 \%)$ na amostra, que possui grande concentração de alunos pardos $(55,1 \%)$ e brancos $(35,5 \%)$. Mais de $82 \%$ dos alunos respondentes exerce ou já exerceu uma atividade remunerada, apontando para um grau razoável de independência financeira. A maioria possui apenas um irmão (43\%) e mora com os pais e os irmãos (46,7\%).

Em se tratando de renda própria, $63,6 \%$ dos alunos não possuem qualquer tipo de renda contra $36,4 \%$ que possuem algum tipo de renda. Recebem até 1,5 salário mínimo, $68,9 \%$ deles, seguido por $19,7 \%$, que recebem entre 1,5 a 3 salários mínimos. Apenas $1,6 \%$ deles estão na segunda maior faixa salarial - de 6 a 10 salários mínimos.

Em relação ao background familiar, é possível identificar que os pais possuem elevada escolaridade, em média. Um total de $28 \%$ das mães possui o ensino médio completo, seguido de $26,2 \%$ que possuem o ensino superior completo. Apenas $12,1 \%$ dos estudantes relataram que as mães possuem ensino fundamental incompleto. A escolaridade do pai segue uma distribuição semelhante à da mãe, mas com uma concentração maior de pais com ensino fundamental incompleto $(17,8 \%)$. Um total de $30,8 \%$ dos pais possui ensino médio completo, seguido de $18,7 \%$ que completou o ensino superior. Na pós-graduação, as mães são maior número (15\%) vis-à-vis os pais, com $8,5 \%$. 
Para $22,4 \%$ dos respondentes, os pais possuem renda entre 1,5 e 3 salários mínimos e 17,8\% possui renda entre 3 e 4,5 salários mínimos. O acesso à TV por assinatura é prevalente para $52,3 \%$ dos estudantes que responderam ao questionário, mas a porcentagem sem acesso a este canal cultural é bastante elevado $(47,7 \%)$.

O uso e consumo de bens culturais pode ser um hábito herdado dos familiares. Em sua maioria, os respondentes citaram o hábito de ir ao cinema, de leitura, de ir a shows e ir a museus e exposições como uma herança cultural de algum familiar.

Embora se considerem agentes moderadamente consumistas $(67,3 \%)$, o perfil dos estudantes em relação às variáveis de consumo cultural indica que a imensa maioria da amostra quase nunca utiliza os equipamentos culturais disponíveis no município (46,7\%). Os que disseram nunca utilizar estes equipamentos somam $11,2 \%$. Os respondentes consideram "moderadamente alta" a importância do consumo de bens culturais (48,6\%) e somente $2,8 \%$ acreditam que o consumo deste tipo de bem possui baixa importância.

A proximidade destes equipamentos às residências poderia servir de estímulo ao uso. Os estudantes indicam que há proximidade destes equipamentos às suas casas $(48,6 \%)$, mas o mesmo percentual ressalta que não há qualquer equipamento cultural próximo a sua casa.

A classificação dos bens de cultura utilizada por esse trabalho foi a elencada por Ana Flávia Machado a fim de que fossem estabelecidos os bens culturais que constituiriam a cesta dos agentes em relação àqueles bens presentes na Pesquisa de Orçamento Familiar (POF-IBGE), a qual divide os bens em diretos e indiretos e em subcategorias, como artigos de decoração, de leitura, áudio, vídeo, idas a cinema, a teatro, a espetáculos de dança, a ópera, a shows etc.

Ao observar as respostas sobre o consumo destes bens culturais, nota-se que ir ao cinema e adquirir artigos de leitura são os bens mais consumidos por $95,3 \%$ e $72,9 \%$ dos respondentes, respectivamente. Em seguida, está o consumo de ingressos de shows $(58,9 \%)$, teatro $(35,5 \%)$ e exposições $(30,8 \%)$. Um total de $27,1 \%$ dos estudantes da amostra respondeu não ter o hábito de consumir artigos de leitura e, quando há, ficam bastante restritos a revistas (48,6\%) e jornais $(40,2 \%)$. Artigos de artesanato decorativo não fazem parte da lista de compras de $71 \%$ dos respondentes. Até mesmo artigos de áudio e vídeo estão fora desta lista para $62,6 \%$ dos discentes. Dentre os que consomem estes artigos, 29\% se propõe a adquirir CDs e 19,6\% compra DVDs.

As saídas para lazer se concentram em bares $(64,5 \%)$ e boates $(46,7 \%)$. Os teatros são locais frequentados por $26,2 \%$ dos estudantes da amostra. O consumo de cursos de dança e de música está restrito a $9,3 \%$ dos respondentes para ambos bens culturais. Em geral, os estudantes da UFC não participam $(78,5 \%)$ de nenhum dos cursos culturais apresentados no questionário. A maioria prefere consumir bens culturais em sua própria residência $(67,3 \%)$.

Nas residências dos alunos, perguntou-se quais aparelhos eram mais utilizados nas atividades cotidianas. Um total de $95,3 \%$ utiliza computador ou notebook, $61,7 \%$ usam frequentemente a TV, seguido de $29,9 \%$ que usam equipamentos de som.

Cerca de $48,6 \%$ dos respondentes declararam que os locais culturais que frequentam estão próximos à universidade e $41,1 \%$ afirma que não costuma frequentar locais culturais próximos à UFC. Com relação aos equipamentos e espaços culturais oferecidos pela própria universidade, os estudantes afirmam, em sua maioria, que nunca utilizam esses ambientes $(70,1 \%)$. Apenas $3,7 \%$ dos respondentes utilizam estes espaços de forma mais frequente. Apesar de pouco utilizarem estes espaços, 
os estudantes acreditam que a universidade poderia oferecer mais espaços culturais e formas de acesso aos dispositivos culturais (84,1\%). Um total de $14 \%$ ressalta que as atividades culturais existentes são suficientes.

A universidade é vista pela maioria dos alunos $(56,1 \%)$ como tendo uma significância moderada na disseminação cultural, enquanto quase $30 \%$ deles afirma que a universidade tem baixa significância na disseminação cultural em Fortaleza.

As respostas dos estudantes indicam que o consumo de bens culturais depende do ciclo social de convivência e, para $71 \%$ deles, começaram a criar um hábito de consumo de bens culturais devido ao convívio e experiências com pessoas próximas ou conhecidas. Eles acreditam também, em sua maioria, que os bens de cultura e os lugares culturais que dão acesso a esses bens devem ser melhor anunciados.

\subsection{Resultados - Probit}

A partir dos dados levantados pelo questionário aplicado, foi construído, para análise do comportamento dos agentes em relação ao consumo em bens e serviços de cultura, representado pela variável dependente dicotômica consbc, um modelo probit com as variáveis descritas na tabela 2 , abaixo.

Tabela 2 - Variáveis utilizadas no modelo

\begin{tabular}{|c|c|}
\hline \multicolumn{2}{|c|}{ Descrição das Variáveis - Modelo Probit } \\
\hline Consbc & $\begin{array}{l}\text { Variável dependente: consumo de bens culturais (se } \\
\text { consome }=1 \text {, e } 0 \text {, caso contrário) }\end{array}$ \\
\hline Bcultuni & $\begin{array}{l}\text { Variável dummy acerca da utilização de bens culturais } \\
\text { dentro da universidade(se utiliza }=1 \text {, e } 0 \text {, caso } \\
\text { contrário) }\end{array}$ \\
\hline Escol & $\begin{array}{l}\text { Anos de estudo nos cursos de graduação } \\
\text { disponibilizados pela universidade }\end{array}$ \\
\hline idade2 & Quadrado da idade dos alunos \\
\hline Rendap & $\begin{array}{l}\text { Variável dummy que expressa se os agentes } \\
\text { possuíam ou não renda própria }\end{array}$ \\
\hline Sexo & $\begin{array}{l}\text { Variável dummy para o sexo dos estudantes (feminino } \\
=1 \text {, e } 0 \text {, caso contrário) }\end{array}$ \\
\hline
\end{tabular}

Fonte: Elaborado pelos autores.

O modelo estimado foi o seguinte:

$$
\operatorname{consbc}_{i}=\text { bcultuni }_{i}+\text { idade }_{i}+\operatorname{escol}_{i}+\operatorname{rendap}_{i}+\operatorname{sexo}_{i}
$$

Os resultados do modelo econométrico são apresentados na tabela $\mathbf{3}$, em seguida. Como não é possível estabelecer uma causalidade entre as variáveis do modelo, o objetivo neste trabalho é apontar se há alguma relação, estatisticamente 
significante, entre as variáveis independentes e a variável indicativa de consumo de bens culturais (consbc).

Ressalte-se que, no modelo probit exposto, a magnitude dos coeficientes não deve ser interpretada de maneira usual porque não reflete o efeito marginal da variável explicativa sobre a variável dependente. Portanto, a análise que se segue diz respeito apenas ao sinal do coeficiente.

A variável qualitativa de utilização de bens culturais na universidade possui um impacto positivo sobre o consumo de bens culturais e foi estatisticamente significante. A variável de escolaridade dos estudantes possui um efeito que segue no mesmo sentido da covariável anterior, ou seja, quanto maior a escolaridade, aqui entendida como anos de estudo nos cursos de graduação da universidade, maior a probabilidade de que o estudante consuma bens e serviços culturais.

A idade dos discentes está negativamente correlacionada com o consumo de bens culturais, uma vez que o coeficiente apresenta sinal negativo e estatisticamente significante. Espera-se, portanto, que indivíduos com mais idade consumam menos bens culturais. Este resultado é corroborado por Castelar, Castelar e Benevides (2012).

Já a variável indicativa de que o aluno possui renda própria não foi estatisticamente significante. Este resultado não causa surpresa uma vez que, ao responder o questionário, a maioria dos estudantes afirmou que busca atividades culturais gratuitas. Destarte, o consumo dos bens culturais não necessariamente está ligado ao fato de o aluno ter ou não renda.

Tabela 3 - Resultados econométricos

\begin{tabular}{ccccc}
\hline Variável & Coeficiente & Erro Padrão & Estatística-z & Prob. \\
\hline bcultuni & $1.227665^{*}$ & 0.305500 & 4.018540 & 0.0001 \\
escol & $0.631103^{* *}$ & 0.319723 & 1.973904 & 0.0484 \\
idade2 & $-0.002330^{*}$ & 0.000614 & -3.794203 & 0.0001 \\
rendap & -0.254735 & 0.314768 & -0.809280 & 0.4184 \\
sexo & -0.308773 & 0.282604 & -1.092601 & 0.2746 \\
\hline $\begin{array}{c}\text { Log } \\
\text { Probabilidade } \\
\text { Médio }\end{array}$ & -0.489969 & Obs com Dep=0 & & \\
\hline
\end{tabular}

Fonte: Elaborado pelos autores. ${ }^{*}$ significante a $1 \% .{ }^{* *}$ significante a $5 \%$.

Por fim, a variável relacionada a sexo indica que o fato de ser do sexo feminino não tem impacto positivo nem negativo sobre o consumo de bens culturais, uma vez que a variável não foi estatisticamente significante. O trabalho de Diniz e Machado (2009) corrobora este resultado, dado que tanto em relação à distribuição de gasto, que foi semelhante tanto para famílias chefiadas por homens quanto por mulheres, bem como os resultados econométricos apontaram que a variável de gênero não foi significante. 


\section{CONCLUSÕES}

Este trabalho buscou analisar o comportamento de consumo de bens culturais dos graduandos da Universidade Federal do Ceará - UFC, por intermédio da aplicação de um questionário para que fossem obtidas informações gerais e específicas dos estudantes em relação às suas práticas de consumo de bens culturais, ao grau de importância que atribuem a esse tipo de consumo, à frequência de consumo, por meio da estimação de um modelo probit, possuindo como variável dependente o consumo de bens de cultura e relacionando-o com variáveis como renda, sexo, idade, utilização de bens culturais dentro da universidade e anos de estudo na graduação.

Foram analisados 107 questionários e o perfil traçado para os alunos da UFC, nesta amostra, indica que a maioria está no $8^{\circ}$ semestre de seus cursos de graduação, é do sexo feminino, com média de idade de 22,5 anos, possui apenas um irmão, é, geralmente, solteiro e pardo.

Mais da metade deles terminou o ensino médio em escola particular e os pais apresentam ensino médio completo como nível de escolaridade mais frequente. Os discentes costumam morar próximos aos centros de cultura, mas, apesar disso, não costumam ir a esses espaços culturais. Portanto, os estudantes priorizam outros tipos de bens que não os culturais para o consumo.

Dentre os bens culturais consumidos, os livros não didáticos são os mais adquiridos e mais da metade deles afirma não ter consumido qualquer artigo de áudio ou vídeo. Cerca de $95 \%$ dos alunos frequentam cinema e 58,9\% vão a shows de música. Os agentes analisados costumam consumir bens culturais em âmbito domiciliar, com conhecidos ou amigos e procuram por atividades gratuitas. Esse consumo reflete a perspectiva geral do Brasil, ao começo do século, como apontado na análise de Da Silva, Araújo e Souza (2007). Cerca de 70\% deles, declararam nunca ter utilizado algum ambiente cultural na universidade e aproximadamente $85 \%$ deles acreditam que essas atividades e espaços de cultura deveriam ser ampliados, o que indica um contrassenso.

Os resultados econométricos do modelo probit indicam que o uso de bens culturais nas universidades tende a aumentar o grau de exposição do agente a esses dispositivos culturais aumentando as suas demandas por esses tipos de bens em específico. Outro fator que tem impacto positivo é a escolaridade dos estudantes. A idade ao quadrado apresentou efeito negativo, mostrando que, quanto maior a idade, menos disposto o aluno está em consumir bens dessa natureza. Possível explicação para tal resultado é que, dado a maior volume de responsabilidades acadêmicas à medida que o discente avança em seu curso, menos tempo disponível tem para outras atividades.

Dados os fatos relatados, parece haver certa desconexão entre atividades e equipamentos culturais disponíveis e a utilização destes pelos discentes da Universidade Federal do Ceará. Considerando o ambiente universitário como um que fomenta informação, ainda assim merece uma discussão mais aprofundada as razões pelo relativo baixo consumo de bens culturais, algo que pode ser estendido como interpretação de fenômeno que ocorre na sociedade como um todo. O primeiro intuito de trabalhos do gênero é sugerir incentivo e aumento de bens culturais em forma de política pública governamental. No entanto, os resultados do presente estudo mostram a importância da discussão com os próprios consumidores sobre sua real demanda por ambientes e equipamentos que fornecem cultura. 


\section{REFERÊNCIAS}

BEM, J.S., WASIMANN, M., FINATTO, J. A transformação do consumo de bens culturais nos domicílios particulares durante o tempo: estudo do município de Canoas entre 2000 e 2010. Economia \& Região, Londrina(Pr), v.2, n.1, p.99-114, ago./dez. 20149

BERMÚDEZ, Emilia. Consumo cultural y construcción de representaciones de identidades juveniles. Universidad del Zulia, Facultad de Ciencias Económicas y Sociales, Centro de Estudios Sociológicos y Antropológicos . Maracaibo, Venezuela. 2010.

BRASIL. Constituição (1988). Constituição da República Federativa do Brasil. Brasília, DF: Senado Federal: Centro Gráfico, 1988.

BRITO, P; BARROS, C. Learning-by-Consuming and the Dynamics of the Demand and Prices of Cultural Goods. Journal of Cultural Economics, v. 29, n. 2, 2005, p. 83-106.

BRYANT, W. D. A.; THROSBY, D. Creativity and the Behavior of Artists. In: GINSBURG, V. A.; THROSBY, D. (eds). Handbook of the Economics of Art and Culture. Amsterdam: Elsevier, v. 1, 2006, cap. 16.

CASTELAR, Ivan; CASTELAR, Pablo Urano de Carvalho; BENEVIDES, Alesandra de Araújo. Determinantes do índice individual de consumo cultural no Brasil. Série Worrking Paper BNDS/ANPEC No. 49. Novembro. 2012.

CASTIGLIONE, C.; INFANTE, D. Rational Addiction and Cultural Goods: The Case of the Italian Theatregoer. Journal of Cultural Economics, v. 40, n. 2, 2016, p. 163-190.

CHENG, S.W. Cultural Goods Creation, Cultural Capital Formation, Provision of Cultural Services and Cultural Atmosphere Accumulation. Journal of Cultural Economics, v. 30, n. 4, 2006, p. 263-286.

CHUNG, C.; SONG, M. Preference for Cultural Goods: Demand and Welfare in the Korea Films Market. Simon School Working Paper n. FR 08-23, jun. 2008. Disponível em: https://ssrn.com/abstract=1349988

COELHO NETTO, José Teixeira. Dicionário crítico de política cultural. São Paulo, SP: Iluminuras/Fapesp, 1997.

DA SILVA, F.B., ARAÚJO, H.E., SOUZA, A.L. O Consumo Cultural das Famílias Brasileiras. In: Gasto e consumo das famílias brasileiras contemporâneas(volume 2). Fernando Gaiger Silveira, Luciana Mendes Servo, Tatiane Menezes e Sérgio Francisco Piola (Organizadores). IPEA. Brasília, 2007

DINIZ, Sibelle Cornélio; MACHADO, Ana Flávia. Análise do consumo de bens e serviços artístico-culturais no Brasil metropolitano. 2009. 
EARP, Fábio de Sá; PAULANI, Leda Maria. Mudanças no consumo de bens culturais no Brasil após a estabilização da moeda. 2014. Nova Economia. Vol. 24. $N^{\circ}$ 3. Belo Horizonte. 2014.

FAVARO, D.; FRATESCHI, C. A Discrete Choice Model of Consumption of Cultural goods: The Case of Music. Journal of Cultural Economics, v. 31, n. 3, 2007, p.205-234.

FELIX, Fabiola Angarten. Juventude e estilo de vida: cultura de consumo, lazer e mídia. 2003.

FERREIRA, Marcelo Costa. Consumo cultural e espaços sociais: os vestibulandos das universidades públicas na cidade do Rio de Janeiro, 1990. 2003. Opinião Pública. Vol 9. n 1. Campinas. 2003.

FORJAZ, Maria cecília Spina. Lazer e Consumo Cultural das Elites. 1988.

FREUDENBERG, B. Change for change's sake: are tax reforms required to assist the Australian arts sector? Cultural Trends, v. 20, n. 1, 2011, p.85-106.

FREIRE FILHO, João. Mídia, consumo cultural e estilo de vida na pósmodernidade. 2003. Revista do Programa de Pós-Graduação em Comunicação e Cultura da Escola de Comunicação da Universidade Federal do Rio de Janeiro. Revista Ecopós. 2003.

GALLOWAY, S.; DUNLOP, S. A Critique of Definitions of the Cultural and Creative Industries in Public Policy. International Journal of Cultural Policy, v. 13, n. 1, 2007, p. 17-31.

GEERTZ, Clifford. Uma descrição densa: por uma teoria interpretativa da cultura. In: A Interpretação das Culturas. Rio de Janeiro: LTC, 1989.

GOODWIN, C. Art and Culture in the History of Economic Thought. In: GINSBURG, V. A.; THROSBY, D. (eds). Handbook of the Economics of Art and Culture. Amsterdam: Elsevier, v. 1, 2006, cap. 2.

GOLDENSTEIN, Gisela Taschner. Lazer operário e consumo cultural na São Paulo dos anos oitenta. 1991. Revista de Administração de Empresas. Vol 31. $n^{\circ} 3$. São Paulo. 1991.

GUJARATI, Damodar N. Econometria Básica. 4ª Edição. 2006. Rio de Janeiro.

GÜNTHER, Hartmut. Como elaborar um questionário. Brasília, DF. 2003.

HESMONDHALGH, D. Media and Cultural Policy as Public Policy: the Case of the British Labor Government. International Journal of Cultural Policy, v. 11, n.1, 2006, p. 95-109. 
KISH, L. Statistical Design for Research. J. Wiley \& Sons. New York, 1987.

MANCEBO, Deise; OLIVEIRA, Dayse Marie; Fonseca, Jorge Guilherme Teixeira da; SILVA, Luciana Vanzan. Consumo e subjetividade: trajetórias teóricas. Rio de Janeiro. 2002.

MASON, R. Modelling the Demand for Status Goods. In: RUDMIN, Floyd W.; RICHINS, Marsha (eds.). Meaning, Measure, and Morality of Materialism. Association for Consumer Research, 1992, p. 88-95.

MENGER, P. M. Artistic Labor Markets: Contingent Work, Excess Supply and Occupational Risk Management. In: GINSBURG, V. A.; THROSBY, D. (eds). Handbook of the Economics of Art and Culture. Amsterdam: Elsevier, v. 1, 2006, cap. 22.

NUNES, Brasilmar Ferreira. Consumo e Identidade no meio juvenil: considerações a partir de uma área popular do Distrito Federal. 2007.

PAGLIOTO, Bárbara Freitas; MACHADO, Ana Flávia. Perfil dos frequentadores de atividades culturais: o caso nas metrópoles brasileiras. Estudos Econômicos. Vol. 42. № 4. São Paulo. 2012.

PASQUALI, L. Psicometria: Teoria e Aplicações. Brasilia, DF. Editora UNB. 1997.

PRIETO-RODRIGUEZ, J.; ROMERO-JORDÁN, D.; SANZ-SANZ, J.F. Is a Tax Cut on Cultural Goods Consumption Actually Desirable? A Microsimulation Analysis Applied to Spain. The Journal of Applied Public Economics, v. 26, n.4, 2005, p. 549-575.

ROBBINS, L. Art and the State. In: Politics and Economics. Lord Robins (aut.). London: Palgrave Macmillan, 1963, cap. 3, p. 53-72.

RONDELLI, Elizabeth. Televisão aberta e por assinatura: consumo cultural e política de programação. 1998.

SIEGEL, S. Estatística Não-Paramétrica Para as Ciências do Comportamento. São Paulo: McGraw-Hill do Brasil. 1975.

SILVA, Frederico A. Barbosa da; ARAÚJO, Herton Ellery. Indicador de Desenvolvimento da Economia da Cultura. 2010.

THROSBY, D. Cultural Capital. Journal of Cultural Economics, v. 23, n. 1-2, 1999 , p. 3-12.

VARELLA, A.Q. O Consumo de Bens Culturais: Uma Abordagem Institucional. Monografia. Universidade Federal do Paraná. Curitiba, 2015. 
WASSALL, G. H.; ALPER, N. O. Toward a Unified Theory of the Determinants of the Earnings of Artists. In: TOWSE, R.; KHAKEE, A. (eds) Cultural Economics. Berlin: Springer, 1992, cap. 18. 